\title{
Seizing the opportunity: tackling fossil fuel subsidies under the UNFCCC
}

\author{
Harro van Asselt ${ }^{1,2} \cdot$ Kati Kulovesi ${ }^{1}$
}

Accepted: 8 March 2017/Published online: 24 March 2017

(C) The Author(s) 2017. This article is an open access publication

\begin{abstract}
Analyses from international and nongovernmental organizations have pointed to the negative environmental, economic and social implications of the sizable subsidies handed out by governments for the production and consumption of fossil fuels. Given their relevance for achieving climate policy objectives, it is perhaps surprising that the climate regime established by the United Nations Framework Convention on Climate Change (UNFCCC) does not address fossil fuel subsidies. This article discusses the possible role of the UNFCCC in tackling fossil fuel subsidies. It suggests that the UNFCCC could enhance the transparency around fossil fuel subsidies and put in place incentives for countries to undertake subsidy reform. However, the possibilites under the UNFCCC will be limited by political barriers to subsidy reform at the national level and will need to be carried out in coordination with other international institutions active in the field.
\end{abstract}

Keywords Energy · Fossil fuel subsidies · Paris Agreement · UNFCCC

$\begin{array}{ll}\text { Abbreviations } \\ \text { COP } & \text { Conference of the Parties } \\ \mathrm{CO}_{2} & \text { Carbon dioxide } \\ \text { GSI } & \text { Global Subsidies Initiative } \\ \text { G20 } & \text { Group of } 20 \\ \text { IEA } & \text { International Energy Agency } \\ \text { IMF } & \text { International Monetary Fund } \\ \text { INDC } & \text { Intended nationally determined contribution } \\ \text { NAMA } & \text { Nationally appropriate mitigation action } \\ \text { NDC } & \text { Nationally determined contribution }\end{array}$

Harro van Asselt

harro.vanasselt@sei-international.org

1 University of Eastern Finland Law School, Joensuu Campus, P.O. Box 111, 80101 Joensuu, Finland

2 Stockholm Environment Institute, 29 Grove Street, OX2 7JT Oxford, UK 


$\begin{array}{ll}\text { NGO } & \text { Nongovernmental organization } \\ \text { OECD } & \text { Organisation for Economic Co-operation and Development } \\ \text { OPEC } & \text { Organization of the Petroleum Exporting Countries } \\ \text { PAMs } & \text { Policies and measures } \\ \text { TEM } & \text { Technical expert meeting } \\ \text { UNFCCC } & \text { United Nations Framework Convention on Climate Change }\end{array}$

\section{Introduction}

When the Paris Agreement was adopted in December 2015, headlines joyfully announced that countries had signed in the end of the fossil fuel era (Goldenberg et al. 2015; Holthaus 2015). Contrary to what the newspaper headlines would seem to suggest, however, the Agreement does not even mention the words 'fossil fuels'. While this may seem surprising, decisions about fossil fuel production and consumption are closely linked to national sovereignty and interests, and energy policy decisions remain by and large the prerogative of national decision-makers. As this article suggests, however, while the topic is politically challenging there may be a role for international law and institutions such as the regime established by the United Nations Framework Convention on Climate Change (UNFCCC) in addressing fossil fuels.

The relationship between fossil fuels and climate change is clear. Anthropogenic climate change mainly results from the combustion of fossil fuels such as coal, oil and gas (with fossil fuel combustion accounting for $69 \%$ of global greenhouse gas emissions in 2010; Blanco et al. 2014, 354). There is an increasing recognition in policy and academic circles that to avoid dangerous climate change, most fossil fuel reserves will need to be left in the ground (IEA 2012; McGlade and Ekins 2015).

Yet climate policy has tended to focus on promoting low-carbon alternatives (e.g. through carbon pricing, energy efficiency standards or renewable energy support), rather than directly tackling fossil fuels. In one important respect, however, this situation has changed: in the past years, governments, analysts, international organizations and nongovernmental organizations (NGOs) have increasingly drawn attention to the subsidies handed out by governments for the production and consumption of fossil fuels. The issue has been taken up in international forums such as the Group of 20 (G20) and the Rio+20 summit, and several international organizations - such as the International Monetary Fund (IMF) and the Organisation for Economic Co-operation and Development (OECD)—and NGOs — such as the Global Subsidies Initiative (GSI) - have provided insights into the scale of such subsidies, as well as their environmental, social and economic implications.

By lowering the costs of fossil energy, fossil fuel subsidies pose a serious barrier for the transition towards a low-carbon economy. Nonetheless, such subsidies are not addressed by the main intergovernmental venue for international cooperation on climate change, the UNFCCC. Although parties to the UNFCCC are free to pursue fossil fuel subsidy reform as a mitigation policy under the climate regime, the UNFCCC, the Kyoto Protocol and the Paris Agreement do not contain rules specific to fossil fuel subsidies. However, as this article argues, the evolution of the climate regime-which is currently transitioning from a system of internationally agreed binding targets towards a system of nationally determined mitigation contributions-offers new opportunities to include fossil fuel subsidies within its scope.

This article examines the potential role for the UNFCCC in tackling fossil fuel subsidies. Following a discussion of the linkages between fossil fuel subsidies and climate 
change (Sect. 2), the article traces how such subsidies have been treated under the UNFCCC historically, and what options are available to climate negotiators and individual governments to start taking up the issue (Sect. 3). The article then sketches the political limitations of some of these options, highlighting that any effort under the UNFCCC needs to take place in concert with efforts by other international institutions, before drawing conclusions (Sect. 4).

\section{Fossil fuel subsidies: a climate change problem}

As highlighted by Van de Graaf and van Asselt (2017), a wide range of estimates of the size of fossil fuel subsidies exist. Although those of the OECD and the International Energy Agency (IEA) are more conservative than the IMF, the size of fossil fuel subsidies is significant in all cases. For instance, the IEA $(2016,97)$ suggests that fossil fuel consumption subsidies were more than twice the size of renewable energy subsidies in 2015.

The estimates vary according to the definition of 'subsidies', the scope of analysis, and the calculation methods employed. 'Subsidies', which could include a range of financial or other support measures taken by governments resulting in benefits for private actors, are notoriously hard to define (WTO 2006, 47-53). While fossil fuel subsidies could be in the form of grants or other direct transfers of funds from the government to private actors, they also could assume other guises, such as market price support (e.g. setting prices above or below market rates), tax concessions (e.g. exemptions or reductions), in-kind support (e.g.. building a railroad from a coal mine to a port), credit support (e.g. favourable loans or loan guarantees), below-market insurance rates and caps on liability, or preferential government procurement (Steenblik 2008, 18-27). With respect to the scope, it matters whether producer subsidies (e.g. support to coal mining or oil and gas exploration) are included in addition to consumer subsidies (e.g. lowering the price of energy use for households or companies). While the former are generally assumed to be smaller than the latter, producer subsidies can nevertheless be sizable. For instance, Bast et al. (2015) suggest that support to fossil fuel production in the G20 amounts to US\$444 billion per year. Lastly, different methods exist for the calculation of subsidies, with the price-gap approach and inventories being the most common approaches (Stefanski 2014; Kojima and Koplow 2015), ${ }^{1}$ but resulting in different outcomes. Altogether, while there are clear indications of the magnitude of fossil fuel subsidies, there remains uncertainty about their specific size.

From the perspective of climate mitigation, it is becoming increasingly evident that fossil fuel subsidies are problematic. For instance, the IEA suggests that consumption subsidies were responsible for $13 \%$ of global carbon dioxide $\left(\mathrm{CO}_{2}\right)$ emissions in 2014 (equivalent to a subsidy of US $\$ 115$ per tonne of $\mathrm{CO}_{2}$ ). In comparison, all the emissions trading schemes in the world in 2014 only covered $11 \%$ of global $\mathrm{CO}_{2}$ emissions (IEA $2015,23)$. This estimate may still be conservative; however, Stefanski $(2014,5)$ estimates that subsidies resulted in up to $36 \%$ of global $\mathrm{CO}_{2}$ emissions between 1980 and 2010. Fossil fuel subsidies further prevent the uptake of renewable energy, as they 'impair the competitiveness of renewable energy technologies, reinforce the continuation of fossilfuel-based systems, and distort investment decisions in favour of fossil-fuel technologies' (Bridle and Kitson 2014, 18).

\footnotetext{
1 The price-gap approach consists of assessing the difference between real prices and prices expected under a free market scenario. The inventory approach consists of adding up the value of support provided under individual measures that can be classified as subsidies (see also Skovgaard 2017).
} 
Fossil fuel subsidies also have other detrimental impacts. Importantly, they put significant pressure on government budgets, with less money being available for other priorities such as health and education. Moreover, in welfare terms, subsidies in developing countries tend to favour the rich (Arze del Granado and Coady 2012; Coady et al. 2015). In addition, fossil fuel subsidies may have indirect local environmental (e.g. air pollution) and social (e.g. health) side effects.

The insights into the implications of fossil fuel subsidies suggest that the case for phasing them out-or otherwise reforming them-is strong (Burniaux and Chateau 2014; Schwanitz et al. 2014; Rentschler and Bazilian 2016). Yet fossil fuel subsidy reform will not be easy. Countries may have adopted subsidies based on valid concerns. For example, consumer subsidies may play an important role in ensuring access to affordable energy, whereas producer subsidies may help countries reduce dependence on imported energy (Bárány and Grigonytė 2015). Moreover, 'interest groups and investments solidify around the existence of the policy and make change difficult' (Victor 2009, 7). And even if subsidy reform takes place, there remains a risk that such reforms will be reversed if the political conditions change (as is evidenced by countries such as Nigeria, which introduced reforms in early 2012 only to abandon them a few weeks later, following public protests).

In short, negatively put, fossil fuel subsidies can be seen as a barrier to achieving climate policy goals. Framed more positively, fossil fuel subsidy reform offers an opportunity to achieve significant emission reductions and economic benefits. The question this article will now look into is whether the UNFCCC can play a role in seizing this opportunity. We answer this question in the affirmative, but also point out that any options for the role of the UNFCCC need to take into account the history of the climate regime and ongoing political sensitivities.

\section{Fossil fuel subsidies and the UNFCCC}

Although several developed and developing countries referred to fossil fuel subsidies in their submissions on issues to be included in the Paris Agreement (Benninghoff 2013), the issue does not feature in the final treaty text or the associated decision on the Agreement's adoption by the UNFCCC Conference of the Parties (COP). This section seeks to shed light on the reasons why this key issue for climate change mitigation has not, to date, been formally included in the UNFCCC regime despite proposals to do so being made since the early 1990s. It shows that the consideration of fossil fuel subsidies under the climate regime has encountered political difficulties in addition to being affected by the general design of the UNFCCC mitigation system. Furthermore, in the light of the mitigation system created by the Paris Agreement, it seems difficult to introduce binding obligations on fossil fuel subsidy reform in the near future. However, the section also highlights that there are several openings to consider the issue in the context of various existing UNFCCC obligations and activities.

\subsection{Energy and fossil fuels in the climate regime: a brief history}

While the link between fossil fuels and climate change has been clear since the inception of the UNFCCC negotiations, the climate regime does not include obligations on energy issues, including fossil fuel subsidies. One of the key reasons is that countries are generally keen to emphasize their national sovereignty over natural resources. They are also prone to 
challenge any supranational effort to govern energy, including fossil fuels. This can be witnessed in other areas of international governance, such as energy trade, but it is also true for well-integrated regions, such as the European Union (Van de Graaf et al. 2010, 103). For the most part of the UNFCCC history, developing countries have also tended to resist the idea of international climate change mitigation obligations, fearing that these would limit their economic development opportunities. Addressing energy governance and fossil fuel subsidies under the UNFCCC therefore links to long-standing concerns over national sovereignty and divides between developed and developing countries.

As negotiations for the Convention were launched in 1990, the prospect of international action to mitigate climate change and reduce the consumption of fossil fuels was a serious concern especially for countries belonging to the Organization of the Petroleum Exporting Countries (OPEC). OPEC members, including Kuwait and Saudi Arabia, sought to emphasize scientific uncertainty over climate change and 'went to great lengths to (...) avoid any reference to energy' in the Convention (Dessai 2004, 19). Their efforts were successful in that the UNFCCC includes no mention of the need to reduce the consumption of fossil fuels.

OPEC members' concerns were also reflected in the Convention's preamble, which recognizes the difficulties of developing countries whose 'economies are particularly dependent on fossil fuel production, use and exportation, as a consequence of action taken on limiting greenhouse gas emissions'. Furthermore, Article 4.8 of the UNFCCC requires the consideration of adverse effects that climate change mitigation measures might have on developing countries. ${ }^{2}$ As a result of the language used, the impacts of mitigation measures (i.e. 'response measures') became directly linked to discussions about the impacts of climate change itself (Depledge 2008; Chan 2016). Listing several groups of countries whose circumstances require special attention when implementing the UNFCCC, Article 4.8 recognizes the special status of 'countries whose economies are highly dependent on income generated from the production, processing and export, and/or consumption of fossil fuels and associated energy-intensive products'. Article 4.10 further requires UNFCCC parties to take into consideration the situation of parties, 'particularly developing country Parties, with economies that are vulnerable to the adverse effects of the implementation of measures to respond to climate change', when implementing their commitments under the Convention. OPEC members' concerns are also reflected in Articles 2.3 and 3.14 of the Kyoto Protocol, which essentially require developed countries to implement their emission reduction commitments 'in such a way as to minimize adverse effects (...) on international trade, and social, environmental and economic impacts on other Parties'.

Subsequently, these issues have been considered under the Subsidiary Body for Implementation and the Subsidiary Body for Scientific and Technological Advice. Examples include the obligation of developed countries to report on their response measures. More recently, the Improved Forum on the Impact of the Implementation of Response Measures institutionalized many of the discussions involving fossil-fuel-producing nations (Chan 2016). This Forum will continue to serve the Paris Agreement (UNFCCC 2015a, paras. 33-34).

This brief history shows that countries' concerns over their national sovereignty, reluctance of developing countries to limit their development options through international

\footnotetext{
${ }^{2}$ Article 4.8 of the UNFCCC provides that '(...) the Parties shall give full consideration to what actions are necessary under the Convention (...) to meet the specific needs and concerns of developing country Parties arising from the adverse effects of climate change and/or the impact of the implementation of response measures'.
} 
mitigation commitments, as well as interests of oil-producing countries have played an influential role in the UN climate negotiations, affecting the contents of the UNFCCC and related legal instruments. These are undoubtedly the key reasons for why the UNFCCC has not addressed the link between climate change and fossil fuels or prescribed related policies, such as removing fossil fuel subsidies.

\subsection{Design of mitigation policies and measures in the climate regime}

The previous section suggested that there has been limited space for the UNFCCC to address fossil fuels specifically. However, possibilities to consider fossil fuel subsidy reform also need to be considered in the context of the overall design of the mitigation system under the UNFCCC regime. In this regard, it is important to note that the climate treaties have always refrained from prescribing specific climate change mitigation policies and measures (PAMs). In other words, they include only very general obligations related to PAMs without requiring any specific measures.

Nonetheless, throughout the history of the climate regime, countries have made proposals to include specific mitigation measures, including those addressing fossil fuel subsidies. For instance, Vanuatu, on behalf of the Alliance of Small Island States, suggested during the negotiations for the UNFCCC that the Convention would need to include a provision specifying a 'prohibition on subsidizing activities which contribute to climate change' (UNFCCC 1991a, 30). Sweden went one step further, calling for a commitment to reduce 'subsidies for the production and use of fossil fuels with a view to abolish [sic] such subsidies at the latest by the year (2000)' (UNFCCC 1991b, 4). Ultimately, however, countries decided against listing any specific mitigation measures that parties would need to adopt. Instead, Article 4.1 of the UNFCCC simply requires all parties to develop PAMs to combat climate change and to report on them, and Article 4.2(a) requires developed countries to 'adopt national policies and take corresponding measures on the mitigation of climate change'. This is coupled with a non-binding target to return their greenhouse gas emissions to the 1990 levels by 2000 as well as an obligation to communicate periodically 'detailed information' on policies and measures that aim to reach this objective.

The key objective of the Kyoto Protocol was to introduce stricter mitigation commitments for developed countries. It did so in the form of binding emission targets, initially for the period from 2008 to 2012 and subsequently from 2013 to 2020. In the negotiations for the Protocol, several UNFCCC parties again proposed a range of specific mitigation PAMs, including the phasing out of fossil fuel subsidies (Depledge 2000, paras. 72-73). This included developed countries such as France, New Zealand, Norway and Switzerland. The latter, for instance, suggested choosing between two approaches, with the first approach consisting of targets for subsidy reduction and the second approach comprising a blanket removal of 'all types of subsidies except those related to research and environmental protection' (UNFCCC 1996, 4). Interestingly, also oil-producing countries put proposals forward, with Iran proposing the removal of coal subsidies 'as the most pollut[ing] source of energy' (UNFCCC 1997, 32).

These proposals were only partially reflected in the final outcome. Article 2.1 of the Kyoto Protocol indicates that each developed country party must 'implement and/or further elaborate policies and measures in accordance with its national circumstances' in achieving its quantified emission target. This general requirement is followed by an indicative list of PAMs. Article 2.1(a)(v) of the Kyoto Protocol refers to '[p]rogressive reduction or phasing out of market imperfections, fiscal incentives, tax and duty exemptions and subsidies in all greenhouse-gas-emitting sectors that run counter to the objective of the Convention and 
application of market instruments' (emphases added). This wording reflects in part the proposals made by parties to reduce fossil fuel subsidies. However, there is no obligation to implement any of the specific policies listed in Article 2.1 of the Protocol. Instead, Parties retain considerable discretion to decide how to mitigate greenhouse gas emissions and in which sectors.

While the Kyoto Protocol has provided the most sophisticated international legal framework for climate mitigation to date, its importance is rapidly diminishing. The first commitment period from 2008 to 2012 included all key developed countries apart from the USA, which never ratified the Protocol, and Canada, which formally withdrew in 2011. The Protocol amendment for the second commitment period from 2013 to 2020 is yet to enter into force but even if it did, also other key developed countries like Japan and Russia have decided to opt out.

The future mitigation framework under the climate regime will be based on the Paris Agreement. The Agreement's key achievements include setting long-term mitigation objectives, engaging all Parties in mitigation action and introducing five-year ambition cycles. The Paris Agreement also includes provisions on enhanced transparency and regular global stocktaking (van Asselt 2016). The Agreement's main substantive provision in Article 4.2 provides that '[e]ach Party shall prepare, communicate and maintain successive nationally determined contributions that it intends to achieve' and that 'Parties shall pursue domestic mitigation measures, with the aim of achieving the objectives of such contributions'. The Agreement thus emphasizes the role of national governments in defining their mitigation ambition and measures in the form of nationally determined contributions (NDCs).

Importantly for the present context, the Paris Agreement also cements the discretionary approach to PAMs under the UNFCCC regime. Given that the Agreement aims to create a durable framework for international climate action and the painstaking efforts to reach the agreement in the first place, its fundamentals are unlikely to be changed anytime soon. In addition, UNFCCC parties are currently facing a packed negotiating agenda to flesh out detailed rules needed to implement the Paris Agreement. Attempts to launch the consideration of obligatory fossil fuel subsidy reform would carry the risk of distracting from this important mandate as well as reopening the delicate political balance struck in the Paris Agreement.

Given the traditionally discretionary approach to PAMs in the climate regime and the legal design of the Paris Agreement emphasizing national discretion, it seems unlikely that UNFCCC parties would adopt binding obligations related to fossil fuel subsidies reform in the foreseeable future. However, our argument is that there are several other opportunities for launching work on fossil fuel subsidies under the UNFCCC, which we turn to next.

\subsection{New opportunities to consider fossil fuel subsidies under the UNFCCC}

As seen above, the question of specific PAMs was a sensitive one under the Kyoto Protocol's architecture of legally binding emission reduction targets. Developed countries were unwilling to commit to specific PAMs, instead preferring general targets that left more leeway to consider national circumstances and priorities. This situation seems, however, different in the context of a non-legally binding mitigation architecture. In other words, the Paris Agreement's emphasis on national discretion in defining mitigation contributions may actually entail a window of opportunity to intensify work on fossil fuel subsidy reform under the auspices of the UNFCCC. 
Many of the mitigation pledges submitted in context of the 2009 Copenhagen Accord, as well as some of the intended nationally determined contributions (INDCs) submitted as part of the Paris Agreement negotiations, include information on specific PAMs that countries intend to implement. For instance, INDCs submitted by the EU, the USA, Russia and Mexico specify the laws and policies put in place to achieve their nationally determined mitigation targets. ${ }^{3}$ Countries thus seem to be more open to considering specific PAMs in the knowledge that neither these PAMs in themselves, nor the emission targets they are aimed at fulfilling, are legally binding.

In our view, and responding to repeated high-level calls to address fossil fuel subsidies, this could open the door for considering fossil fuel subsidies and their reform under the UNFCCC. Below, we examine specific options for doing so, followed by a consideration of the political feasibility of these options, and the extent to which the role of the UNFCCC could and should complement efforts aimed at fossil fuel subsidies in other international forums in Sect. 3.4.

\subsubsection{Improved reporting on fossil fuel subsidies and measures to reform them}

As a first option, countries could report on (policies related to) fossil fuel subsidies and their reform in their regular reports to the UNFCCC. This can already be done under the current reporting system and be taken into consideration when negotiating detailed rules for the enhanced transparency framework under Article 13 of the Paris Agreement.

In the current national communications submitted to the UNFCCC, both developed country (Annex I) and developing country (non-Annex I) Parties are free to report fossil fuel subsidy data under information in the chapter on 'national circumstances'. In addition, Annex I Parties could add further information on reform efforts under the 'policies and measures' heading and non-Annex I Parties under the heading of 'general description of steps taken or envisaged to implement the Convention' (Benninghoff 2013, 5).

Similarly, relevant information on fossil fuel subsidies can be included under the reporting system agreed upon as part of the 2010 Cancún Agreements, which introduced biennial reports for developed countries and biennial update reports for developing countries. Developed countries can offer information in the section on 'mitigation actions and their effects' of the biennial report, whereas developing countries can include information in the section on 'mitigation actions' of the biennial update report.

A key provision in the Paris Agreement is the enhanced transparency framework under Article 13, which will apply to both developed and developing countries. Work to develop the detailed modalities, procedures and guidelines in accordance with Article 13 was launched in May 2016 and is scheduled to be finalized by COP 24 in 2018. This work provides a concrete opportunity for parties to go beyond existing reporting guidelines and offer more specific guidance on the reporting of fossil fuel subsidies and measures to reform them. To ensure that every party will indeed follow through, such guidance could be made mandatory, perhaps initially only for developed country parties. Although this will inevitably meet with resistance from at least some parties, it would offer an opportunity to provide a government-driven knowledge base about fossil fuel subsidies worldwide.

Ideally, to ensure comparability and foster a greater understanding of the extent of fossil fuel subsidies globally, a common definition of 'subsidies' would be welcome. However, given the fact that each country will likely hold different views on what constitutes a

\footnotetext{
${ }^{3}$ http://www4.unfccc.int/submissions/indc/Submission\%20Pages/submissions.aspx.
} 
subsidy — as is also evident from the reporting to the G20 (Aldy 2015)—reporting could be limited to what each party defines as a subsidy. The resulting system would by no means provide complete clarity about the full extent of fossil fuel subsidies of UNFCCC parties, but would help increase transparency about what different parties argue are their subsidies. This could pave the way for more detailed consideration of fossil fuel subsidies under the UNFCCC in the future.

\subsubsection{Fossil fuel subsidy reform as a nationally appropriate mitigation action}

A second option to consider fossil fuel subsidies under the UNFCCC regime would be for developing countries to carry out fossil fuel subsidy reform as a nationally appropriate mitigation action (NAMA) (Benninghoff 2013). The concept of NAMAs originated in the 2007 Bali Action Plan, which was ground-breaking in launching work on developing country mitigation. Several developing countries communicated their NAMAs in context of the Copenhagen Accord. Further work has been undertaken under the UNFCCC to match NAMAs with support, and a NAMA registry listing actions communicated by parties was established to this end.

Developing countries interested in carrying out fossil fuel subsidy reform as a NAMA could communicate this information to the UNFCCC Secretariat and request support. Support does not have to be limited to financial flows, but could also be aimed at enhancing the technical capacity to understand the extent of subsidies, or generally building institutional capacity (cf. Cheon et al. 2013). Moreover, in some cases it may be sensible to use NAMAs to tie fossil fuel subsidy reform to measures promoting alternative energy sources, which could increase the climate change mitigation benefits.

Although after Paris, the concept of NAMAs may seem to have been overtaken by the notion of nationally determined contributions, NAMAs are still expected to play an important role in the implementation of NDCs by developing countries (Afanador and Gardiner 2016). Moreover, some developing countries may still wish to include fossil fuel subsidy reform in NAMAs in the pre-2020 period.

\subsubsection{Inclusion of fossil fuel subsidy reform in NDCs}

NDCs are at the heart of the mitigation system created by the Paris Agreement. According to Article 4.2, each party is obliged to 'prepare, communicate and maintain successive NDCs' as well as to pursue domestic mitigation measures to achieve the NDC's objective. Each successive NDC must be progressively more ambitious than the previous one, reflecting the party's 'highest possible ambition' as well as parties' 'common but differentiated responsibilities and respective capabilities, in the light of different national circumstances'.

NDCs reflect the main climate mitigation contributions parties are willing to undertake under the Paris Agreement. Thus far, guidance on the contents of NDCs has remained relatively open-ended (UNFCCC 2015a, para. 27). Arguably, this 'lack of standardization' has left countries with increased flexibility to include the types of information they deem useful (Merrill et al. 2015, 8). The range of mitigation policies and actions in countries' NDCs could take the form of either specific actions and their expected outcomes, or defining the outcome (e.g. an emissions target) and listing key PAMs through which the target will be achieved. In our view, this opens the door for encouraging countries to include fossil fuel subsidy reform in their NDC. 
The inclusion of fossil fuel subsidies in an NDC could take the form of 'describing plans to reform producer and consumer subsidies and through estimating emissions reductions from these policy changes', and developing and emerging countries could 'include estimated emission reductions from recent, anticipated and planned subsidy reforms within their INDCs' (Merrill et al. 2015, 8). Terton et al. (2015) found that 13 countries included references to fossil fuel subsidy reform in their INDCs in the run-up to Paris. For instance, Ethiopia's INDC indicates that the country has 'already removed fossil fuel subsidies to enable enhanced generation and use of clean and renewable energy' (Ethiopia 2015, 7). Morocco (2015) goes one step further, committing to '[s]ubstantially reducing fossil fuel subsidies, building on reforms already undertaken in recent years'. In other words, some countries have already started to seize this opportunity. Although it is unlikely that many countries will make significant changes when turning their INDC into an NDC, subsequent rounds of preparation and submission of NDCs will offer new and repeated opportunities for countries to incorporate fossil fuel subsidy reform in their climate plans.

\subsubsection{Pre-2020 action}

The mandate launching the negotiations on the Paris Agreement also included a separate negotiating track-known as 'workstream 2'-focusing on scaling up climate action before 2020. An important element of this work consisted of a series of mitigation-oriented technical expert meetings (TEMs) that have been mandated to continue at least until 2020.

At these meetings, governmental and nongovernmental experts share experiences and views on specific actions, technologies and policies with high mitigation potential. The TEMs thus far have focused on topics such as energy efficiency in urban environments, renewable energy, non- $\mathrm{CO}_{2}$ greenhouse gases and $\mathrm{CCS} .{ }^{4}$ Although fossil fuel subsidy reform was proposed as the topic of a possible TEM by some countries, including New Zealand (2013), it has not been the subject of a dedicated meeting. However, given that the TEM process will continue, it is possible for future TEMs to address fossil fuel subsidy reform. In this regard, it can be noted that the regular technical papers prepared in relation to the TEMs have repeatedly highlighted fossil fuel subsidy reform as an option for increasing mitigation ambition (see, e.g. UNFCCC 2016b, 23-24).

\subsubsection{Reducing financial support for high-emission investments}

Parties to the Paris Agreement could also try to elaborate on its Article 2, which specifies that one of the goals of the treaty is to '[make] finance flows consistent with a pathway towards low greenhouse gas emissions and climate-resilient development'. Although this provision does not mention fossil fuel subsidies as such, financing the continued production and consumption of fossil fuels is most certainly not in line with 'a pathway towards low greenhouse gas emissions and climate-resilient development'.

The negotiating history of the Paris Agreement lends some support to this interpretation. In the Geneva negotiating text adopted in February 2015, which formed the basis for the final negotiations, reducing fossil fuel subsidies was mentioned twice in the section on finance (UNFCCC 2015b, paras. 34ter and 53.1(d)). During 2015, the reference to fossil fuel subsidies morphed into a reference to reducing (and providing information on) international support for high-emission investments (UNFCCC 2015c, paras. 62 and 63(h)), and references moved from the draft treaty text to the draft COP decision. Although

\footnotetext{
$\overline{4}$ http://unfccc.int/focus/mitigation/technical_expert_meetings/items/8179.php.
} 
these provisions were ultimately removed to finalize the deal in Paris, Article 2 of the Paris Agreement still offers an important signal to reduce investments in fossil fuel production and consumption. In further developing the rules for implementing the Paris Agreementand particularly its provisions on finance and reporting thereof-it may be possible to bring questions concerning financial support for high-emission investments back into the discussions on climate finance, with reference to Article 2. Parties could in this context also refer to the 'Roadmap to US\$100 Billion', in which a range of developed country parties outlined how they envisage meeting the collective goal of providing US $\$ 100$ billion of climate finance (from public and private sources) by 2020. The Roadmap points to fossil fuel subsidy reform as a way to transform financial flows (UNFCCC 2016a, 22-23).

\subsubsection{Global phase-out goal}

A final option would be to adopt a COP decision including specific language on the phasing out of fossil fuel subsidies in the future, or acknowledging that this goal has been adopted in the context of other international forums. For instance, the outcome document of the Rio+20 Summit in 2012 suggests that '[c]ountries reaffirm the commitments (...) to phase out harmful and inefficient fossil fuel subsidies that encourage wasteful consumption and undermine sustainable development' (UN 2012, para. 225). Similarly, at the 2009 G20 summit in Pittsburgh, heads of government decided to 'rationalize and phase out over the medium term inefficient fossil fuel subsidies that encourage wasteful consumption' (G20 2009). More recently, the G7 added a specific deadline of 2025 (Mathiesen 2016).

Reiteration of such goals would not necessarily mean that the UNFCCC would play a stronger role in the monitoring of whether this goal is being met, but it could offer an important signal that the goal is supported by the international community of developed and developing countries and that fossil fuel subsidy reform is seen as a legitimate and useful tool to achieve climate policy objectives.

\subsection{The role of the UNFCCC: opportunities and limitations}

Other options to address fossil fuel subsidies and promote their reform in the UNFCCC context may well be conceivable. However, the feasibility of some options may be constrained by the political economy of the climate regime: as discussed above (Sect. 3.2), oil-producing countries have often (but not always) resisted attempts to address fossil fuel subsidies under the UNFCCC. Furthermore, questions concerning energy touch upon delicate areas of national sovereignty making some countries wary of attempts to include such issues in international negotiations. Combined with the already full agenda and consensus rule of the UNFCCC, this may make some options (e.g. mentioning phase-out goals or specific guidelines for reporting subsidies) difficult to achieve (Lang et al. 2010).

Nonetheless, the changing architecture of the climate regime provides opportunities for some of the other options, including voluntary reporting on subsidies and their reform, putting forward subsidy reform as a NAMA, its inclusion in NDCs and discussing experiences in the context of TEMs. These options do not require consensus and can be adopted by one or several parties that wish to set an example. A particular role could be played here by the Friends of Fossil Fuel Subsidy Reform, a coalition of smaller, non-G20 developed and developing countries, whose aims to increase support 
for fossil fuel subsidy reform would fit well with piloting some of the options outlined above (see also Young 2017). ${ }^{5}$

It should be remembered that, in addressing fossil fuel subsidies, the UNFCCC is not stepping into an institutional vacuum. Importantly, a range of other international institutions have sought to enhance transparency of the size and scope of subsidies (Van de Graaf and van Asselt 2017). This means that any reporting guidance related to fossil fuel subsidies under the UNFCCC would benefit from streamlining guidance with these efforts, building upon already existing coordination between relevant institutions (e.g. IEA et al. 2011). Similarly, as mentioned above, a global phase-out target under the UNFCCC could build on what has already been achieved in other venues (notably the G20 and the G7).

\section{Conclusions}

This article has explored possibilities to address fossil fuel subsidies through the UNFCCC. Any such analysis has to start with the reasons why fossil fuels and energy have received limited attention in the UNFCCC thus far. A brief overview of the history of the climate regime shows that the close connections between energy policy decisions and national sovereignty, and reluctance of fossil-fuel-producing nations to discuss those linkages in the context of climate change, have meant that energy and fossil fuels have received only limited mentions in the climate treaties so far. This also holds for the recent Paris Agreement.

This is not to say that the climate regime cannot play a role at all. The article highlighted six opportunities for the UNFCCC to start addressing fossil fuel subsidies: (1) voluntary reporting of subsidies and their reform by Parties; (2) including fossil fuel subsidy reform as a NAMA; (3) including fossil fuel subsidy reform in NDCs; (4) discussing fossil fuel subsidy reform as a measure with high mitigation potential in future TEMs; (5) reviving the idea of reducing support for high-emissions investments in the context of future climate finance discussions and (6) reiterating the commitment to phase out inefficient fossil fuel subsidies by 2025 , as agreed by the G7.

On a concluding note, the role of international institutions such as the UNFCCC is unlikely to extend to directly limiting fossil fuel subsidies or obliging phase out or reform. However, this does not mean that international institutions do not have a role to play in putting in place incentives for countries to undertake fossil fuel subsidy reform. Such incentives can be informational: by strengthening the transparency of the size and scope of subsidies through reporting and review, it is possible to obtain better insights into their environmental, economic and social implications. Enhanced transparency can also trigger reputational incentives: other countries as well as domestic stakeholders can hold governments to account for meeting pledges made about fossil fuel subsidy reform. In addition, international institutions can put in place financial and other economic incentives, particularly for developing countries: by indicating clearly that fossil fuel subsidy reform is part of a country's mitigation portfolio, the likelihood increases that such actions can be eligible for support. Even though subsidy reform at the national level is more likely to be triggered by economic and fiscal motivations, the climate regime could strengthen the case for reform by offering these incentives.

\footnotetext{
5 The Friends released a Communiqué at the end of 2015, calling on countries to translate high-level commitments into action. The Communiqué was supported by a diverse group of countries and non-state actors, going beyond the Friends countries. See http://fffsr.org/communique/.
} 
Open Access This article is distributed under the terms of the Creative Commons Attribution 4.0 International License (http://creativecommons.org/licenses/by/4.0/), which permits unrestricted use, distribution, and reproduction in any medium, provided you give appropriate credit to the original author(s) and the source, provide a link to the Creative Commons license, and indicate if changes were made.

\section{References}

Afanador, A., \& Gardiner, A. (2016). NAMAs from the perspective of developing countries. http:// mitigationpartnership.net/sites/default/files/namas_from_the_perspective_of_developing_countries. pdf.

Aldy, J. E. (2015). Policy surveillance in the G-20 fossil fuel subsidies agreement: Lessons for climate policy. Climatic Change. doi:10.1007/s10584-015-1505-0.

Arze del Granado, F. J., \& Coady, D. (2012). The unequal benefits of fuel subsidies: A review of evidence for developing countries. World Development, 40(11), 2234-2248.

Bárány, A., \& Grigonytė, D. (2015). Measuring fossil fuel subsidies. Brussels: European Commission.

Bast, E., Doukas, A., Pickard, S., van der Burg, L., \& Whitley, S. (2015). Empty promises: G20 subsidies to oil, gas, and coal production. Washington, DC: Oil Change International and Overseas Development Institute.

Benninghoff, V. (2013). Prioritizing fossil-fuel subsidy reform in the UNFCCC process: Recommendations for short-term actions. Geneva: GSI.

Blanco, G., Gerlagh, R., Suh, S., Barrett, J., de Coninck, H. C., Diaz Morejon, C. F., Mathur, R., Nakicenovic, N., Ofosu Ahenkora, A., Pan, J., Pathak, H., Rice, J., Richels, R., Smith, S. J., Stern, D. I., Toth, F. L., \& Zhou, P. (2014). Drivers, trends and mitigation. In O. Edenhofer, R. Pichs-Madruga, Y. Sokona, E. Farahani, S. Kadner, K. Seyboth, A. Adler, I. Baum, S. Brunner, P. Eickemeier, B. Kriemann, J. Savolainen, S. Schlömer, C. von Stechow, T. Zwickel, \& J. C. Minx (Eds.), Climate change 2014: Mitigation of climate change. Contribution of working group III to the fifth assessment report of the intergovernmental panel on climate change (pp. 351-411). Cambridge: Cambridge University Press.

Bridle, R., \& Kitson, L. (2014). The impact of fossil-fuel subsidies on renewable electricity generation. Geneva: GSI.

Burniaux, M., \& Chateau, J. (2014). Greenhouse gases mitigation potential and economic efficiency of phasing-out fossil fuel subsidies. International Economics, 140, 71-88.

Chan, N. (2016). The 'new' impacts of the implementation of climate change response measures. Review of European, Comparative and International Environmental Law, 25(2), 228-237.

Cheon, A., Urpelainen, J., \& Lackner, M. (2013). Why do governments subsidize gasoline consumption? An empirical analysis of global gasoline prices, 2002-2009. Energy Policy, 56, 382-390.

Coady, D., Flamini, V., \& Sears, L. (2015). The unequal benefits of fuel subsidies revisited: Evidence for developing countries. Washington, DC: IMF.

Depledge, J. (2000). Tracing the origins of the Kyoto protocol: An article-by-article textual history. UN Doc. FCCC/TP/2000/2.

Depledge, J. (2008). Striving for no: Saudi Arabia in the climate change regime. Global Environmental Politics, 8(4), 9-35.

Dessai, S. (2004). An analysis of the role of OPEC as a G77 member at the UNFCCC. Report for the World Wildlife Fund.

Ethiopia. (2015). Intended nationally determined contribution (INDC) of the Federal Democratic Republic of Ethiopia. http://www4.unfccc.int/submissions/INDC/Published\%20Documents/Ethiopia/1/INDCEthiopia-100615.pdf.

G20. (2009). Leaders' statement. Pittsburgh Summit, 24-25 September. http://www.g20.org/sites/default/ files/g20_resources/library/Pittsburgh_Declaration.pdf.

Goldenberg, S., Vidal, J., Taylor, L., Vaughan, A., \& Harvey, F. (2015). Paris climate deal: Nearly 200 nations sign in end of fossil fuel era. The Guardian.

Holthaus, E. (2015). Paris Agreement ushers in end of the fossil fuel era. The Slatest.

IEA. (2012). World energy outlook 2012. Paris: IEA.

IEA. (2016). World energy outlook 2016. Paris: IEA.

Kojima, M., \& Koplow, D. (2015). Fossil fuel subsidies: Approaches and valuation. Washington, DC: World Bank.

Lang, K., Wooders, P., \& Kulovesi, K. (2010). Increasing the momentum of fossil-fuel subsidy reform: A roadmap for international cooperation. Winnipeg: IISD.

Mathiesen, K. (2016). G7 nations pledge to end fossil fuel subsidies by 2025. The Guardian. 
McGlade, C., \& Ekins, P. (2015). The geographical distribution of fossil fuels unused when limiting global warming to $2{ }^{\circ} \mathrm{C}$. Nature, 517(7533), 187-190.

Merrill, L., Harris, M., Casier, L., \& Bassi, A. M. (2015). Fossil-fuel subsidies and climate change options for policy-makers within their intended nationally determined contributions. Copenhagen: Nordic Council of Ministers.

Morocco. (2015). Intended nationally determined contribution (INDC) under the UNFCCC. http://www4. unfccc.int/submissions/INDC/Published\%20Documents/Morocco/1/Morocco\%20INDC\% 20submitted \%20to\%20UNFCCC\%20-\%205\%20june\%202015.pdf.

IEA, OPEC, OECD, \& World Bank. (2011). Joint report by IEA, OPEC, OECD and World Bank on fossilfuel and other energy subsidies: An update of the G20 Pittsburgh and Toronto commitments. http:// www.oecd.org/env/49090716.pdf.

New Zealand. (2013). Submission to the Ad Hoc Working Group on the Durban Platform for enhanced Action. http://unfccc.int/files/documentation/submissions_from_parties/adp/application/pdf/adp_new_ zealand_workstream_2_20131011.pdf.

Rentschler, J., \& Bazilian, M. (2016). Reforming fossil fuel subsidies: Drivers, barriers and the state of progress. Climate Policy. doi:10.1080/14693062.2016.1169393.

Schwanitz, V. J., Piontek, F., Bertram, C., \& Luderer, G. (2014). Long-term climate policy implications of phasing out fossil fuel subsidies. Energy Policy, 67, 882-894.

Skovgaard, J. (2017). The devil lies in the definition: Competing approaches to fossil fuel subsidies at the IMF and the OECD. International Environmental Agreements: Politics, Law and Economics. doi:10. 1007/s10784-017-9355-z.

Steenblik, R. (2008). A subsidy primer. Geneva: GSI.

Stefanski, R. (2014). Dirty little secrets: Inferring fossil-fuel subsidies from patterns in emission intensities. Oxford: University of Oxford.

Terton, A., Gass, P., Merrill, L., Wagner, A., \& Meyer, E. (2015). Fiscal instruments in INDCs: How countries are looking to fiscal policies to support INDC implementation. Geneva: GSI.

UN. (2012). The future we want. Outcome document of the United Nations Conference on Sustainable Development Rio de Janeiro, Brazil, 20-22 June 2012. http://sustainabledevelopment.un.org/content/ documents/733FutureWeWant.pdf.

UNFCCC. (1991a). Preparation of a framework convention on climate change. Set of informal papers provided by delegations, related to the preparation of a Framework Convention on Climate Change. UN Doc. A/AC.237/Misc.1/Add.3.

UNFCCC. (1991b). Preparation of a framework convention on climate change. Set of informal papers provided by delegations, related to the preparation of a framework convention on climate change. UN Doc. A/AC.237/Misc.1/Add.6.

UNFCCC. (1996). Implementation of the Berlin Mandate. Proposals from parties. UN Doc. FCCCC/ AGBM/1996/Misc.2/Add.3.

UNFCCC. (1997). Implementation of the Berlin Mandate. Proposals from parties. UN Doc. FCCCC/ AGBM/1997/Misc.1.

UNFCCC. (2015a). Decision 1/CP.21, adoption of the Paris Agreement. UN Doc. FCCC/CP/2015/10/Add.1.

UNFCCC. (2015b). Negotiating text. Advance unedited version 12 February 2015. http://unfccc.int/files/ bodies/awg/application/pdf/negotiating_text_12022015@2200.pdf.

UNFCCC. (2015c). Draft Paris Outcome. Proposal by the President. http://unfccc.int/resource/docs/2015/ cop21/eng/da02.pdf.

UNFCCC. (2016a). Roadmap to US\$100 billion. http://www4.unfccc.int/Submissions/Lists/OSPSubmissionUploa d/261_295_131233554162587561-Roadmap\%20to\%20the\%20US\$100bn\%20(UNFCCC).pdf.

UNFCCC. (2016b). The social and economic value of carbon and the promotion of efficient public transport and energy efficiency of vehicles. Bonn: UNFCCC.

van Asselt, H. (2016). International climate change law in a bottom-up world. Questions of International Law, 6, 5-15.

Van de Graaf, T., Lesage, D., \& Westphal, K. (2010). Global energy governance in a multipolar world. Aldershot: Ashgate.

Van de Graaf, T., \& van Asselt, H. (2017). Introduction to the special issue: Energy subsidies at the intersection of climate, energy and trade Governance. International Environmental Agreements: Politics, Law and Economics. doi:10.1007/s10784-017-9359-8.

Victor, D. G. (2009). The politics of fossil fuel subsidies. Geneva: GSI.

WTO. (2006). World trade report 2006. Exploring the links between subsidies, trade and the WTO. Geneva: WTO.

Young, M. A. (2017). Energy transitions and trade law: Lessons from the reform of fisheries subsidies. International Environmental Agreements: Politics, Law and Economics. doi:10.1007/s10784-017-9360-2. 